\title{
DIGITAL TRANSFORMATION LEVEL INDICATORS OF BANKS
}

\author{
Olha Zamaslo', Viktor Kovalenko², Olha Lozynska
}

\begin{abstract}
The article studies the approach to assessing the banking digitalization influenced by economy digitalization, dynamically spread electronic payments, e-commerce, and innovative digital service technologies. Digitalized banking services, widespread online platforms and digital customer communication channels require an approach to assessing the banking digitalization identifying the bank's competitiveness, strengths and weaknesses strategically. The aim is to develop a banking digitalization indicator system and assessment methods within a complex indicator. To achieve this, the research applied generalization, grouping, systematization to form a grouped indicator system; static, dynamic, structural indicator assessment methods; normalization and integration by arithmetic mean. This approach utilizes the banking digitalization indicators systematically generalized by three groups: digital banking platform indicators; bank's digital service indicators; indicators of digital communications with the bank's customers. Each group provides a flexible indicator set to track the changing banking digitalization trends. Outlining the mathematical transformation of indicators into a single integrated indicator determines the use of innovative products and services and substantiates the areas of ensuring competitiveness and improving the bank's development strategy. While assessing the banking digitalization, this approach grants the following advantages: this analytical tool monitors, analyses, and assesses the banking digitalization trends; banks will realize the strengths and weaknesses of digital tools to ensure the banking market competitiveness; competitive positioning of a bank in the banking service market; analysing, assessing, and positioning improve the bank's development strategy, relevant technologies, and digital transformation tools. Future research should consider an approach to improving the development of the bank's marketing strategy utilizing digital technologies.
\end{abstract}

Key words: assessment, indicator, competitive position, digital tools, digital services, digital channels, digital platforms.

JEL Classification: G21, L11, L13

\section{Introduction}

Digital transformation represents a dynamic direction in improving banking. It identifies new customer interaction forms, processes, and banking products. Digital transformation and implemented FinTechs provide innovative functions for banking institutions and determine the key competition priorities in the sector. According to the annual Digital Banking Maturity review (Deloitte, 2020), in 2020, banks increased the introduction of new digital tools and processes, such as: account opening (by 34\%), remote customer identification and verification (by $23 \%$ ), and distance payments (by $18 \%$ ).

\footnotetext{
Corresponding author:

${ }^{1}$ Ivan Franko National University of Lviv, Ukraine.

E-mail: olha.zamaslo@lnu.edu.ua

ORCID: https://orcid.org/0000-0001-7128-8425

${ }^{2}$ Ivan Franko National University of Lviv, Ukraine.

E-mail: vkovalenko29@ukr.net

ORCID: https://orcid.org/0000-0003-2946-1364

${ }^{3}$ Simon Kuznets Kharkiv National University of Economics, Ukraine.

E-mail: olgalozinskaya1@gmail.com

ORCID: https://orcid.org/0000-0003-2882-3546

Scopus Author ID: 57220577967
}

Establishing the fact of digital transformation in the banking sector requires the development of a digital transformation strategy by banking institutions, which, in turn, necessitates the planning and monitoring of key digitalization indicators and measuring the banking business transformation progress to adjust to the changing market. Moneythor's assessment (2018) of 54 banks in 13 countries suggests that only $46 \%$ of banks clearly outline the results of applying their digital transformation strategy and devote a part of their reports to the deliverables of their digital metrics and determining the dynamics of these indicators. The remaining $54 \%$ of banks present the digitalization 
indicators in different sections of their reports, and metrics are often expressed in approximate figures not compared to the previous years' results.

Therefore, the growth trends in digital banking transformation worldwide shape the urgent need to establish a basic set of indicators that reflect the level of adoption and use of digital technologies while creating, distributing, and regulating banking services.

\section{Literature review}

Assessing the digital transformation level currently forms one of the main tasks in engineering a strategic vision for the development of banks. International analytical organizations, consulting agencies, and scientists dedicate their works to finding an approach to such assessment. However, the methods and models, fragmentary indicators used to assess the digitalization of banking institutions are limited.

The Alliance for Financial Inclusion, a leading international organization for financial inclusion policy and regulation, aims to expand access to high-quality financial services around the world. The Alliance's Digital Financial Services Working Group has developed a basic set of financial inclusion indicators to standardize key indicators and maximize their suitability and practicality for the AFI members (Alliance for Financial Inclusion, 2019). The selection criteria are as follows: usefulness and relevance, conciseness, specificity, and simplicity of data collection. The whole indicator set is measured taking into account:

- access (percentage of administrative units with digital banks, number of digital financial services agents per 10,000 adults; number of active digital financial services agents per 10,000 adults; number of payment points per 10,000 adults; percentage of adult population with registered digital financial services accounts;

- use (percentage of active digital financial services accounts; digital financial services transactions (by volume) per registered account; value of digital financial services transactions, including cash in/cash out, bill payments, bank payments, P2P transfers, disbursement and repayment of loans (microfinance loans), G2P payments, salary payments, value chain payments, e-commerce payments, etc.);

- quality (disclosure requirement, number of complaints per 10,000 active digital financial services accounts, percentage of complaints resolved, transaction failure, dispute resolution, financial literacy) (Alliance for Financial Inclusion, 2019).

This approach is appropriate for assessing the digital transformation of the banking sector as a whole and quite fragmentarily characterizes a particular banking institution in its digitalization.

Moneythor (2018) indicates the most common digital transformation indicators that are analysed and published by banks. They include:
- a percentage of the customer base of digital financial services ( $67 \%$ of banks);

- an increase percentage in the customer base of digital financial services ( $63 \%$ of banks);

- a volume of digital financial services transactions ( $48 \%$ of banks);

- an increase percentage in the volume of digital financial services transactions ( $48 \%$ of banks).

Both static and dynamic indicators should be noted, i.e. banking institutions analyse the transformation of digital banking, which forms the main goal of banking.

At this point, it seems necessary to emphasize the reasonable conclusions made by Moneythor:

- digital transformation indicators are relatively hidden in published bank reports;

- the most common indicators include the number of active users and the volume of digital transactions;

- most banks do not publish the results of digital transformation indicators;

- digital transformation indicators are measured at a simplified level (Moneythor, 2018).

Scholars also put attention on assessing the digital transformation of banking institutions.

The indicators used by Mbama (2018) include quality of digital services, involvement of employees and consumers in digital transformation, susceptibility of digital services and their risk.

Qun et al. (2019) analyse organizational innovations, technological innovations, new interactions with customers, and new revenue models in digital banking.

Internet banking is studied by Amin (2016), Raza et al. (2015), and Martins et al. (2014). For these purposes, the authors use the indicators of service quality and bank customers' satisfaction with these services according to the following parameters: security of digital transactions, informativeness of the bank's website, its convenience and ease of use, and listed online services. To determine digital transformation, the scientists apply a method of expert assessments of respondents.

Ali and Ali (2014) consider mobile banking as an aspect of the digital transformation of banking. While analysing mobile banking, the authors use the following indicators: services offered by mobile banking to meet customer needs; quickness; mobile access; advertising and functionality; quality of service in terms of awareness, reliability, accessibility, accuracy, sensitivity, courtesy and usefulness; transaction efficiency in terms of privacy and security; ease of use, simplicity, timeliness, confidentiality; costs of using mobile banking: equipment costs, access costs and transaction fees; risk related to the service.

Jun and Palacios (2016) establish the following criteria for assessing mobile banking: convenience of mobile applications and their functions, accuracy, ease of use, and version upgrades. 
Bidarra et al. (2013), engaged in mobile banking research, assess the security, confidentiality, usefulness, ease of use, trust, and risks associated with digital services provided through mobile applications.

Dootson et al. (2016) explore social networks as a tool to maximize the banking product benefits and improve the dialogue with the banking service consumer. The authors use the method of expert surveys, their processing using regression models and t-tests to assess the perceived usefulness of social networks in banking for the customer, the latter's intention to use social networks to interact with the financial institution.

A separate unit for assessing the digital banking transformation is determining the level of its effectiveness. Wheelock and Wilson (2017), Plotnikova and Kudryavtseva (2020), Ovidiu and Alina (2015), and Bataev and Plotnikova (2019) devote their works to this aspect. The authors determine the impact exerted by digital bank indicators on profits, determine the parameters affecting the assessment of the digital bank efficiency, formulate econometric models to analyse the assessment of the banks' efficiency.

Thus, the assessment of digital banking transformation is widely studied by practitioners and scholars. However, the lack of a systemic approach to creating an indicator set to measure the banking digitalization level, their suitability for the analysis of tools while forming a marketing strategy of banking, assessment, and monitoring of the banking institution's competitive capacity are of great importance. It is necessary to form methods that are instrumental in quantifying the level of the digital banking transformation as qualitative assessment often provides inaccurate results, which depend on the expert group composition.

\section{Aims and methods}

This study aims to develop a system of the digital banking transformation indicators and methods of their assessment within a complex indicator.

The following tasks require full completion to achieve this aim:

- systematizing the digital transformation parameters according to the set of criteria and characteristics and determining the indicators of the digital banking transformation level by each parameter. To implement this task, generalization, grouping, and systematization methods were used;

- identifying the methods for analysing the digital banking transformation indicators. The methods of static, dynamic, and structural assessment of indicators were proposed to accomplish this task;

- grounding the methods of a quantitative assessment of indicators and their consolidation. Normalization and integration by the arithmetic mean method were recommended while completing this task.

\section{Discussion}

The studied literature sources afford grounds to systematize the digital banking transformation parameters by the following characteristics:

- digital banking platforms;

- digital services provided by the bank;

- digital communications with the bank's customers.

Digital banking platforms comprise Internet banking and mobile banking. Digital banking channels are also represented by ATMs, digital kiosks and/or POS machines, and mobile terminals.

The indicators peculiar to this digital transformation characteristic should quantitatively assess the channel popularity among the users to develop appropriate plans aimed at increasing the number of consumers and the volume of the bank's digital services. With this object in mind, it is advisable to calculate, monitor, and analyse:

- the static indicators: popularization of digital platforms among the banking service consumers (number of visitors to the bank's website within a certain period (a month, a quarter, or a year); number of registered users of the bank's mobile applications; number of branded online inquiries; number of ATMs, POS machines, and mobile terminals) and volume of transactions through digital platforms (volume of transactions performed through the bank's website within a certain period (a month, a quarter, a year); the volume of transactions through the bank's mobile applications; the volume of the ATMs, POS machines, and mobile terminal transactions);

- dynamic indicators: popularization of digital platforms among the banking service consumers (an increased number of sign-ins on the bank's website within a certain period (a month, a quarter, a year); an increased number of registered users of the bank's mobile applications within a certain period (a month, a quarter, or a year); an increased number of ATMs, POS machines, and mobile terminals) and the volume of transactions through digital platforms (an increased volume of transactions performed through the bank's website within a certain period (a month, a quarter, a year); an increased volume of transactions through the bank's mobile applications within a certain period (a month, a quarter, a year).

Based on surveys and the experts' involvement, it is possible to further assess the quality and functionality of online platforms:

- automation and ease of use of the platform (the assessment is targeted at virtual assistance in digital operations);

- functionality (for example, utility service payments, opening loans and deposits, ordering credit and debit cards, etc.);

- design and ergonomics of the platform (the assessment addresses the compatibility with devices and software 
(iOS, Android, Windows, browser), adaptation to languages, availability of platform user settings);

- navigation, including search tools and ease of finding the necessary information;

- cybersecurity and information security.

The assessment of the digital banking service indicators is directed at identifying areas of digital strategy for the banking development in terms of products and services, which might help increase profitability.

Alliance for Financial Inclusion (2019) systematizes the digital service assessment indicators by the following categories:

- mobile wallets;

- branchless banking transactions;

- electronic wallets, i.e. electronic money accounts, including debit cards, NFC/RFID cards, etc.

However, such a classification is significantly limited. For the purposes of digital transformation assessment, it is proposed to systematize digital services by the following features:

- by the customer type: digital services to individuals, legal entities, and individual entrepreneurs (business banking);

- by the banking service content: deposit, credit, online utility service payment, online insurance, and other non-bank financial transactions, payment transactions by debit and credit cards, etc.;

- by the automatized details entry: through details, QR-codes;

- by the payment method: from debit and credit cards, from the Internet card, with electronic money, etc.

It is suggested that the dynamics of the number of customers who have used the service and the transaction volume are analysed by banking services. As recommended by Moneythor (2018), it is also advisable to determine the proportion of the customer base using a certain digital banking service.

Assessing the indicators of digital communications with the bank's customers forms the third aspect of the assessed level of the digital banking transformation. These include the ability to use social networks (Facebook, Instagram etc.), messenger chatbots (Telegram, Viber etc.) to establish long-term productive relationships with the bank's customers through consulting services, advice, information about banking products and services. In this way, banks can increase their revenues using the best communication strategies.

This assessment is designed to determine the communication channel effectiveness for the development of appropriate plans to increase the consumer number and the bank's volume of digital services.

The indicators aimed to assess digital communications can reflect:
- the number of general and individual consultations and advice provided in a particular communication channel;

- the number of responses to questionnaires posted on a particular communication channel;

- the number of subscribers on social networks.

These should also be analysed by static, dynamic, and structural indicators.

Figure 1 provides a systematic generalization of the digital banking transformation indicators.

To determine the integrated level of digital banking transformation for the purposes of forming a competitive strategy, it is necessary to provide a comparative assessment of the bank's competitive position in the sector. Accordingly, the collected statistics require processing pursuant to the following steps:

- formation of a digital transformation indicator database divided into three groups (Figure 1) and built on the data of the country's banks from open sources; - considering that different indicators can be presented in different scales and units of measurement, it is necessary to normalize the indicators by the MINIMAX method in the range $[0 \ldots 1]$, where the minimum and maximum scaled values correspond to 0 and 1 , respectively, by the following formula:

$$
X_{i j}^{\prime}=\frac{X_{i j}-X_{j \min }}{X_{j \max }-X_{j \min }} ;
$$

where $X_{i j}^{\prime}$ is the normalized value of indicator $j$ of bank $i$;

$X_{i j}$ is the actual value of indicator $j$ of bank $i$;

$X_{j \text { min }}$ is the minimum value of indicator $j$ for the group of surveyed banks;

$X_{j \max }$ is the maximum value of indicator $j$ for the group of surveyed banks;

- integration of the normalized indicators into a complex indicator reflecting the competitive capacity of each bank by three groups with the help of the arithmetic mean method. This intermediate stage will reveal the aspect in which a single bank holds a leading competitive position, or lags behind competitors;

- integration of indicators by three groups into a single indicator of the digital banking transformation level with the help of the arithmetic mean method. It is possible to perform a verbal assessment of the integrated level of digital banking transformation according to the Harrington scale:

$0.8-1.0$ is a very high level of digital banking transformation;

$0.63-0.8$ is a high level of digital banking transformation;

$0.37-0.63$ is an average level of digital banking transformation;

$0.2-0.37$ is a low level of digital banking transformation;

$0-0.2$ is a very low level of digital banking transformation. 


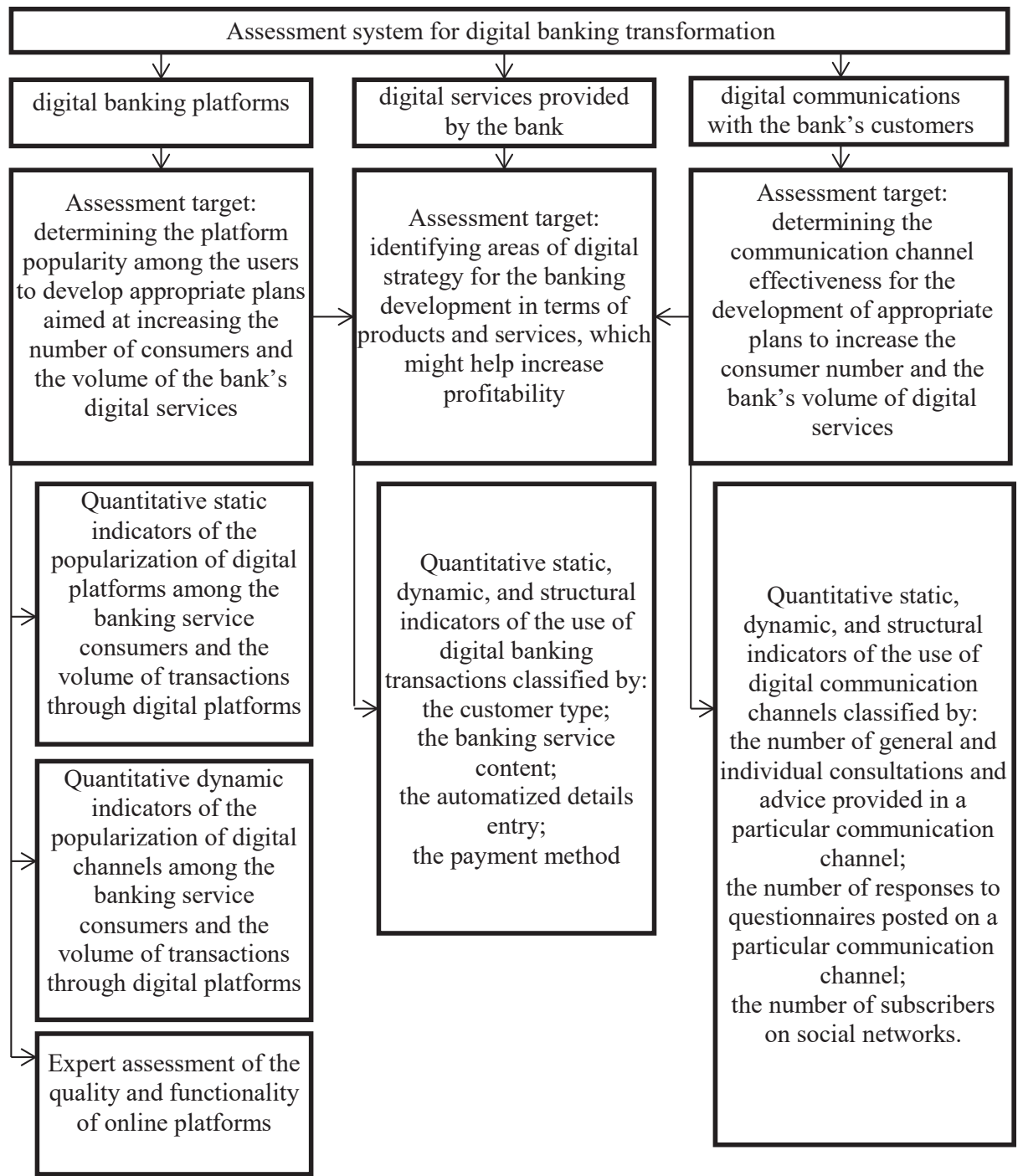

Figure 1. Assessment system for digital banking transformation

Source: developed by the authors

An alternative to assessing the integrated level of digital transformation is ranking to establish the bank's rating among the surveyed ones.

This systemic approach to determining the level of digital banking transformation provides a basis for analysing the competitive position and presents the grounds for forming the banking institution's development strategy. Realizing the problems and advantages while providing digital services, using online platforms and digital communication channels determines the success in the bank's competitive scenario in today's rapidly changing trends of the financial market.

\section{Conclusion}

Digital transformation of banking services, the widespread introduction of online platforms and digital channels of communication with customers determine the need to develop an approach to assessing the digital banking transformation level, which would identify the bank's competitive position, its strengths and weaknesses in the strategic dimension.

Three groups, namely, the indicators of digital banking platforms, indicators of digital services provided by the bank, and indicators of digital communications with the bank's customers, are parts of the systematic generalization of the bank's digital transformation indicators forming the base for the approach proposed by this article. For each group, this study provides a flexible set of indicators that are instrumental in tracking the changing trends in banking digitalization. The approach to the mathematical transformation of indicators into a single integrated indicator outlined in the work offers means for determining the level of use of innovative products and services and helps substantiate the 
areas of competitiveness and improve the bank's development strategy.

The application of the proposed approach to assessing the digital banking transformation level grants the following advantages:

- the proposed approach represents an analytical tool for monitoring, analysis, and assessment of trends in the digital banking transformation;

- banking institutions will be able to realize the strengths and weaknesses of the used digital tools to ensure competitiveness in the banking market;
- enabling competitive positioning of a single bank in the banking service market;

- the results of analysis, assessment, and positioning make it possible to improve the development strategy, relevant technologies, and tools of digital transformation in a banking institution.

In terms of the direction for future research, it should focus on an approach to improving the process of developing the bank's marketing strategy based on digital technologies.

\section{References:}

Ali, A., \& Ali, H. (2014). Customers' perception of m-banking adoption in kingdom of Bahrain: an empirical assessment of an extended tam model. International Journal of Managing Information Technology, 6(1), 1-13.

Alliance for Financial Inclusion (2019). Digital financial service indicators. Guideline Note No. 33. Available at: https://www.afi-global.org/sites/default/files/publications/2019-07/AFI_GN33_DFS_AW_Digital.pdf

Amin, M. (2016). Internet Banking Service Quality and its Implication on e-Customer Satisfaction and e-customer Loyalty. International Journal of Bank Marketing, 34(3), 280-306. doi: 10.1108/IJBM-10-2014-0139

Bataev, A. V., \& Plotnikova, E. V. (2019). Assessment of digital banks' performance. Espacios, 40(20), 24.

Deloitte (2020). Digital Banking Maturity 2020. Available at: https://www2.deloitte.com/content/dam/Deloitte/ ce/Documents/financial-services/ce-digital-banking-maturity-2020.pdf

Dootson, P., Beatson A., \& Drennan, J. (2016). Financial institutions using social media - do consumers perceive value? International Journal of Bank Marketing, 34(1), 9-36.

Jun, M., \& Palacios, S. (2016). Examining the Key Dimensions of Mobile Banking Service Quality: An Exploratory Study. International Journal of Bank Marketing, 34(3), 307-326.

Martins, C., Oliveira, T., \& Popovic, A. (2014). Understanding the Internet Banking Adoption: A Unified Theory of Acceptance and Use of Technology and Perceived Risk Application. International Journal of Information Management, 34(1), 1-13.

Mbama, C. (2018). Digital banking, customer experience and bank financial performance: UK customers' perceptions. International Journal of Bank Marketing, 36(2), 230-255.

Moneythor (2018). Digital banking engagement: where are the metrics? Available at: https://www.finextra.com/ blogposting/15949/digital-banking-engagement-where-are-the-metrics

Ovidiu, S., \& Alina, S. (2015). The impact of internet banking on the performance of Romanian banks: DEA and PCA approach. Procedia Economics and Finance, 20, 610-622.

Plotnikova, E., \& Kudryavtseva, T. (2020). Factors Influencing Digital Bank Performance. Digital Science 2019, 325-333. doi: 10.1007/978-3-030-37737-3 29

Qun, Zh., Tsai, P.-H., \& Wang, J.-L. (2019). Improving Financial Service Innovation Strategies for Enhancing China's Banking Industry Competitive Advantage during the Fintech Revolution: A Hybrid MCDM Model. Sustainability, 11, 1419. doi: 10.3390/su11051419

Raza, S. A., Jawaid, S. T., Hassan, A., \& Burton, B. (2015). Internet Banking and Customer Satisfaction in Pakistan. Qualitative Research in Financial Markets, 7(1), 24-36.

Silva Bidarra, S. H., Henrique, S., Muñoz-Leiva, F., \& Liébana-Cabanillas, F. (2013). Analysis and modeling of the determinants of mobile banking acceptance. The International Journal of Management Science and Information Technology (IJMSIT), NAISIT Publishers, Toronto, 8 (Apr-Jun), 1-27.

Wheelock, D. C., \& Wilson, P. W. (2017). The evolution of scale economies in US banking. Journal of Applied Econometrics, 33, 16-28. 